\title{
Cuidado paliativo oncológico: percepção dos cuidadores
}

\section{Oncological palliative care: perception of caregivers}

\author{
Adrielly Sena Cunha ${ }^{1}$ (D) Jullyana Sousa Pitombeira ${ }^{1} \mathbb{D}$, Tatiana Menezes Noronha Panzetti²,3,4 (D)
}

1. Enfermeira pela Faculdade Integrada Brasil Amazônia (FIBRA), Belém, PA, Brasil. 2. Docente do curso de enfermagem pela Universidade do Estado do Pará (UEPA), Belém, PA, Brasil. 3. Docente do curso de enfermagem pela Faculdade Integrada Brasil Amazônia (FIBRA), Belém, PA, Brasil. 4. Mestre em enfermagem pela Universidade do Estado do Pará.

\section{Resumo}

Introdução: o processo de terminalidade é um dos momentos mais significativos da vida, devido consequências negativas, emocionais e físicas que atingem pacientes e cuidadores. Objetivo: descrever e analisar a percepção do cuidador principal frente a um familiar em cuidado paliativo e traçar o perfil sócio demográfico dos cuidadores familiares. Método: pesquisa exploratória e descritiva de abordagem qualitativa realizada com 10 cuidadores principais de pacientes oncológicos em cuidado paliativo no Hospital Ophir Loyola (HOL). A coleta de dados ocorreu após a aprovação do Comitê de Ética da Faculdade Metropolitana da Amazônia (FAMAZ), no 2.324.920, e pelo Comité de Ética do HOL, no 2.423.239. Para obtenção dos dados, feito entrevista semiestruturada com um instrumento que contemplou o perfil sócio demográfico e perguntas sobre as percepções de ser cuidador. Empregada nas entrevistas a técnica de análise de conteúdo, emergindo assim cinco categorias: percepção do cuidador principal sobre cuidado paliativo; papel do cuidador em cuidados paliativos; sentimentos vivenciados pelo cuidador; dificuldades e estratégias de apoio enfrentadas pelo cuidador; vivências relacionadas ao ambiente hospitalar e domiciliar. Resultados: notou-se que a maioria dos participantes desconhecia o que é cuidado paliativo, e a minoria demonstrou conhecer, por meio de expressões como "alívio da dor". De 10 participantes, 9 eram do sexo feminino, e 6 tinham relação parental. Conclusão: há a necessidade de profissionais oferecerem um cuidado humanizado, considerando as percepções, as necessidades e os sentimentos do cuidador e de realização de educação em saúde para promover segurança no cuidado com o paciente e sensibilização quanto ao autocuidado.

Palavras-chave: Oncologia. Cuidados Paliativos. Cuidador. Enfermagem.

\begin{abstract}
Introduction: The termination process is one of the most significant moments of life due to negative, emotional and physical consequences that affect patients and caregivers. Objective: to describe and analyze the perception of the primary caregiver vis-à-vis a relative in palliative care and to trace the socio-demographic profile of family caregivers. Method: exploratory and descriptive qualitative approach performed with 10 main caregivers of cancer patients in palliative care at Ophir Loyola Hospital (HOL). Data collection took place after approval by the Ethics Committee of the Metropolitan Amazonian Faculty (FAMAZ), no 2,324,920, and by the Ethics Committee of the Hol, no 2,423,239. To obtain the data, a semi-structured interview was performed with an instrument that included the socio-demographic profile and questions about the perceptions of being a caregiver. Employed in the interviews the technique of content analysis, thus emerging five categories: perception of the primary caregiver on palliative care; role of the caregiver in palliative care; feelings experienced by the caregiver; difficulties and support strategies faced by the caregiver; experiences related to the hospital and home environment. Results: most of the participants were unaware of what palliative care was, and the minority demonstrated their knowledge through expressions such as "pain relief". Of 10 participants, 9 were female, and 6 were parental. Conclusion: there is a need for professionals to offer a humanized care, considering the perceptions, needs and feelings of the caregiver and the achievement of health education to promote safety in patient care and awareness of self-care.
\end{abstract}

Key words: Oncology. Palliative care. Caregiver. Nursing.

\section{INTRODUÇÃO}

Presume-se que, aproximadamente, 5 a 6 milhões de pessoas morrem de câncer anualmente. Estima-se, que para o Brasil no biênio 2018-2019, a ocorrência de 600 mil casos novos de câncer, para cada ano. Exceto o câncer de pele não melanoma (cerca de 170 mil casos novos), ocorrerão 420 mil casos novos de outros tipos de câncer. A Organização Mundial de Saúde - OMS estima que, por volta de 2020, cerca de 70\% dos já anunciados, 20 milhões de novos casos de pessoas diagnosticadas com câncer ocorrerão em países em desenvolvimento, principalmente em regiões com precárias condições de acesso aos serviços de saúde ${ }^{1-2}$.

A atenção à pessoa com câncer deve se concentrar nos cuidados ofertados, que vão desde os iniciais durante a internação e ambulatório, até os cuidados no momento da morte, o que compreende os cuidados paliativos. Tratar de um assunto como o câncer é sempre difícil e aflitivo, dificuldades que não ocorrem apenas com o portador da patologia².

Nesse contexto, o cuidado paliativo (CP) se apresenta como uma modalidade de tratamento a partir de uma abordagem que desenvolve qualidade de vida aos pacientes que enfrentam problemas de doenças que ameacem a continuidade da vida e seus familiares, por meio da prevenção e do alívio do sofrimento ${ }^{3}$. Além do que visa promover uma mudança na relação profissional de saúde-paciente-familiares, em que 
se espera haver, por parte da equipe de saúde, uma postura participativa, envolvendo também a família no transcurso do tratamento, abrindo uma via de comunicação e colaboração entre eles ${ }^{4}$.

Entende-se que o processo de terminalidade é um dos momentos mais significativos da vida, não apenas pela condição de ser inevitável, mas, principalmente, pelas consequências negativas, emocionais e físicas que atingem tanto pacientes como familiares e cuidadores que convivem com essa situação ${ }^{5}$.

No entanto, nota-se que geralmente a equipe multiprofissional considera as necessidades do paciente em detrimento das do cuidador, sendo-Ihe omissa. Sem levar em conta que o cuidador se sente sobrecarregado a nível físico, financeiro, emocional, social e existencial, particularmente quando o tempo de dedicação ao enfermo é prolongado ${ }^{6-7}$.

Com relação à temática, constatou-se que há um número significativo de produções científicas sobre cuidados paliativos; no entanto, poucos estudos sobre a família, sendo ela quem mais está perto e mais se dedica ao portador de câncer, muitas vezes, tornando-se o cuidador principal deste indivíduo. Abrindo então a possibilidade da pesquisa abordar o cuidador e a importância da enfermagem considerar a família do paciente em cuidado paliativo.

A partir desse entendimento de que o cuidador também sofre com o adoecimento, vem à tona a seguinte indagação: qual a percepção de ser cuidador de paciente com câncer em cuidado paliativo? E para responder a esse questionamento foram traçados como objetivos: descrever e analisar a percepção do cuidador principal em face de um familiar em cuidado paliativo e traçar o perfil sócio demográfico dos cuidadores familiares.

\section{METODOS}

Optou-se pela realização de uma pesquisa de abordagem qualitativa do tipo exploratória descritiva. A pesquisa qualitativa procura diminuir a distância entre a teoria e os dados, para então compreender os fenômenos pela sua descrição e interpretação ${ }^{8}$.

A pesquisa foi realizada nas dependências do Hospital Ophir Loyola (HOL), na Clínica de Cuidados Paliativos Oncológicos (CCPO). Com o consentimento do mesmo para publicação dos resultados encontrados, sendo citado na publicação o nome do HOL como local da pesquisa.

O estudo foi realizado com 10 (dez) cuidadores principais cuja maioria tinha algum parentesco com os portadores de câncer que estavam em cuidado paliativo.

Os dados foram coletados no dia 02 de outubro até dia 15 de novembro de 2017, concluído após atingirmos o ponto de saturação que se deu com a repetição das respostas e de seus sentidos. Foram excluídos menores de 18 anos, e cuidadores que prestavam apoio ao familiar por um período inferior a 15 (quinze) dias.

Os participantes do estudo foram localizados no campo de pesquisa, por meio de uma visita prévia aos acompanhantes de familiares com câncer em cuidado paliativo, posteriormente selecionamos conforme os critérios de inclusão.

As entrevistas foram aprazadas conforme disponibilidade dos acompanhantes em relação ao dia e ao horário. Durante a entrevista, foram expostos os objetivos do estudo, a necessidade de gravação da entrevista em áudio digital e a leitura do TCLE, ressaltando sobre a garantia do anonimato - sendo utilizado para cada entrevistado o sistema alfa numérico -, quanto a privacidade, a entrevista foi individualizada e aconteceu em local apropriado e reservado na Clínica de Cuidados Paliativos Oncológicos (CCPO).

Para a obtenção dos dados da pesquisa, foi aplicado um roteiro semiestruturado com questões sobre o perfil sociodemográfico e outras específicas relativas às percepções de ser cuidador para direcionar as entrevistas, as quais foram realizadas com auxílio de um gravador digital.

A análise das entrevistas foi realizada de acordo com a técnica de análise de conteúdo, do tipo temático, que envolveu a pré-análise do conteúdo das entrevistas transcritas na íntegra, exploração do material ou codificação, tratamento dos resultados, inferência e interpretação, permitindo, assim, o surgimento de categorias e subcategorias a partir da identificação das expressões-chave, ideias principais e organizadas as falas em categorias temáticas ${ }^{9}$.

Conforme exigências legais, o projeto passou por apreciação no Comitê de Ética em Pesquisa em Seres Humanos, assegurado na Resolução no. 466/12 do Conselho Nacional de Saúde CNS, que trata sobre pesquisas que envolvem seres humanos, valendo-se de princípios da bioética. $O$ estudo foi aprovado pelo Comité de Ética da FAMAZ, sob protocolo no 2.324.920, e pelo Comité de Ética do HOL, sob protocolo no 2.423.239.

\section{RESULTADOS}

\section{Participantes do estudo}

Antes de apresentar a análise propriamente dita, é importante descrever o perfil sociocultural dos cuidadores. Cabe ilustrar que os sujeitos são geradores de experiências e compartilham com seus grupos, influenciando relações e escolhas de vida.

Foram entrevistados 10 participantes, a idade variou de 25 a 54 anos, sendo a média de 42 anos. Houve a prevalência de cuidadores do sexo feminino correspondente a 9 mulheres e a 1 homem. Quanto ao estado civil, 6 são solteiros e 4 casados. Há equilíbrio entre cuidadores ativos no emprego e 
desempregados em número de 5 . Todos os participantes tinham algum grau de escolaridade e declararam ter alguma religião ou crença. Os dados levantados sobre a renda mostraram que 5 tem 1 salário mínimo como renda familiar, mas ressalta-se que houve 1 desses cuidadores com nenhuma renda familiar. Foi possível constatar, segundo o tipo de parentesco dos cuidadores principal com o paciente que 6 correspondiam a irmão, tia, cunhada, neto, primo e cônjuge com apenas 1 . Quanto ao tempo de acompanhamento do cuidador principal ao paciente 5 responderam "Outros", período que variava de 3 a 6 anos. Apesar de que as outras pessoas, que ajudavam o cuidador principal no cuidado do ente enfermo, serem todos da família - 5 eram irmãos - a frequência dessa ajuda era pequena, 4 recebiam ajuda "Ocasionalmente", e somente $1 \mathrm{deu}$ como resposta "Muitas vezes", mostrando o aumento do risco de desgaste do cuidador principal.

A seguir, serão apresentadas as categorias temáticas que emergiram da análise das falas dos participantes.

\section{1) Percepção do cuidador principal sobre cuidado paliativo}

Nessa categoria descrevemos a percepção que alguns participantes da pesquisa possuem em relação ao tema "Cuidado Paliativo". Entendendo ser uma modalidade de tratamento em pacientes que possuem doenças sem possibilidade de cura e são vivenciadas, cotidianamente, pelos cuidadores, portanto a importância de descrever a percepção do tema de forma particular. De 10 participantes entrevistados, 7 não tinham conhecimento algum e tão pouco arriscaram dizer do que se trata o cuidado paliativo, que foram descritas com as expressões "Não sei", ao qual constatamos que acompanham seu paciente em cuidado paliativo, mas não conhecem sobre a modalidade de tratamento.

"Não sei nada não, é a primeira vez que estou ouvindo essa palavra, sinceramente". (A3)

“O que é isso? Eu não sei”. (A4)

Alguns participantes demonstram ter algum conhecimento sobre o tema por meio de expressões associadas ao quadro de ser uma doença incurável, de proporcionar analgesia e alívio de dor.

“[...] é quando o paciente já não tem um quadro que dê opção de uma cirurgia ou opção de uma quimioterapia, que já é o cuidado mais para cuidar da dor [...]." (A1)

“É quando o paciente deixa de receber um tratamento em cima da doença e já vem para cá só para fazer alguma medicação para amenizar a dor [...] é quando é desenganado pelo médico." (A7)

Um cuidador descreveu a assistência em cuidado paliativo, como um processo de diminuir o sofrimento de seu ente querido, seja por meio de atenção, diálogo, paciência, carinho e diminuição da dor física e emocional.

“[...] tem que ter bastante paciência com o paciente, que consiga conversar minimizando o sofrimento daquela pessoa [...] tem que tentar amenizar a dor dela." (A5)

Assim, observamos que a maioria não sabe descrever a essência da assistência em cuidados paliativos oncológicos e descrevem como constatado nas primeiras falas, "não sei", mas uma minoria soube descrever pela vivência diária como cuidador principal, percepção da gravidade clinica e complicações do estado de doença de seu ente querido, como sendo um cuidado necessário a aliviar o sofrimento físico e psicológico do doente de câncer em cuidados paliativos através do controle da dor, carinho e atenção familiar.

\section{2) Papel do cuidador em cuidados paliativos}

Nessa categoria descreve-se a percepção do cuidador em relação ao seu papel de cuidar de um familiar com câncer. Os participantes associaram o seu papel como cuidador a questões sentimentais em oferecer amor, carinho, mas também ressaltaram que para exercer esse papel, são necessários companheirismo, disponibilidade e renúncia ao seu cotidiano de vida. Como identificamos nas falas a seguir:

“[...] Cuidador, é dar amor, dar atenção, é aquele momento que mais precisa a gente se doar, abrir mão de outras coisas para cuidar mesmo de verdade." (A1)

"É estar cuidando do paciente, visando o bemestar dele, a melhora dele, fazer companhia, incentivar[...]" (A7)

Outros ainda agregaram a esse papel ter conhecimento sobre sintomas da doença e poder fazer parte da assistência direta ao paciente.

"[...] ser muito paciente, muito atencioso $\mathrm{e}$ entender os sintomas que ela apresenta sobre a doença [...] passar carinho o máximo que você poder passar." (A6)

"Ter paciência, ter amor, cuidar [...] ter carinho, [...] saber lidar com aquela pessoa tanto fisicamente quanto psicologicamente através de conversas, através de diálogos [...]" (A10)

Portanto, observamos nas falas dos cuidadores que eles têm a percepção da importância de seu papel como cuidador: de entender sobre o desenvolvimento e agravamento da doença, necessidades físicas e emocionais, de apoiar, incentivar, entender e dar amor. Ações, tão necessárias no momento ao sofrimento humano. 


\section{3) Sentimentos vivenciados pelo cuidador}

Nos relatos observamos que ao desempenhar o papel de cuidador este vivencia sentimentos ditos positivos e de aspectos negativos. Os sentimentos negativos relatados foram de: tristeza, desconforto, choro, caracterizado como horrível, sensação de impotência, e dificuldade em suportar o futuro de finitude, como percebemos nas falas a seguir:

“Eu me sinto muito triste, porque não é fácil hoje em dia cuidar principalmente de um irmão, já cuidei da minha mãe com câncer [...] não é fácil. (A2)

"É horrível, é uma sensação que eu não desejo para ninguém" (A10)

"Me sinto muito triste dela estar assim nessa situação [...] eu nem gosto de falar porque eu até choro" (A4)

Apesar de situações e sentimentos carregados de tristeza e incertezas, surgiram sentimentos positivos, como perseverança, força e doação.

Os sentimentos negativos descritos apontam para uma percepção carregada de muita emoção, decorrentes, do afeto pelo ente querido que vivencia uma situação de doença sem cura. O cotidiano desse cuidador é uma experiência complexa e muito sofrida que vai além da doença, pois irá acarretar mudanças de atitude, de vida e de comportamentos do cuidador.

[...] estou tendo que ser muito forte para conseguir cuidar dela, vendo o sofrimento dela, vendo ela chorar dia e noite pedindo para que eu não deixe ela morrer [...]. Eu estou como se estivesse anestesiada, mas eu estou ciente das coisas [...]" (A5)

"Importante, porque tudo o que faço, eu faço com amor, quando a gente tem que se doar para alguém, ajudar alguém tem que ser de verdade, é a prioridade [...] eu abro mão de tudo para cuidar dela." (A1)

Assim, ao mesmo tempo em que a sua dedicação como cuidador é vista como ato de amor, fica claro na leitura dos relatos que os cuidadores acabam por abdicar do cuidado voltado para si e suas outras atividades cotidianas, passando a centrar sua atenção no enfermo. Apresentando sentimentos positivos de ser parte importante no processo de cuidado a um ente querido, com um forte sentimento de renúncia a seu cuidado de si.

4) Dificuldades e estratégias de apoio enfrentadas pelo cuidador.

Nesta unidade, os cuidadores relataram as situações marcantes que tiveram destaque na vivência do cuidado ao seu ente querido. As situações mais marcantes tiveram relação com as complicações do câncer, dificuldades respiratórias, além de falta de informação sobre condutas adequadas, sentimento de coação, permeados de sentimentos de dor e sofrimento.

"A dificuldade maior são as dores [...] porque as dores são muito intensas e às vezes a medicação não está fazendo efeito. [...] eu fico preocupada achando que quando chegar a falta de ar, o que que eu vou ter que fazer, isso me preocupa [...]" (A1)

\begin{abstract}
"Muitos momentos, a gente se sente assim, um descaso total por conta do tempo de demora, por conta da falta de informação [...] isso causa problema até para o cuidador, problema psicológico, problemas emocionais [...] me sinto em algumas situações até agredido [...] a gente acaba também sofrendo como se a gente fosse agredir o profissional com alguma pergunta, há momentos que eu prefiro ficar calado, já com medo do que eu vou ouvir. [...] para você chegar até aqui é um sofrimento [...]" (A9)
\end{abstract}

A evolução da doença, a piora do paciente, o cuidado direcionado e a espera da cura são características frequentes na vivência dos cuidadores, sendo, muitas vezes, percebidos como sofrimento e dor. Muitos dos cuidadores, durante a entrevista, apresentaram-se chorosos e tensos enquanto pensavam sobre o futuro do seu ente sob seus cuidados. Tais comportamentos permitem inferir que o cuidador sofre psicologicamente, figurando-se em um ser desesperançoso quanto a uma reação positiva na melhora do familiar, tendo suas ações por vezes ameaçadas pela sinestesia entre a dor, o sofrer e a impotência frente ao cuidado.

As fontes de apoio são significativas, o que contribui para obter informações, estratégias para enfrentar as adversidades e oferecer suporte emocional. Sendo assim, pode-se observar a necessidade dessa fonte de apoio para alguns cuidadores. A maioria busca o apoio social informal (amigos, parentes, pessoas próximas), o apoio social formal (profissionais do hospital) e o apoio espiritual (religião ou crença) conforme os relatos.

A fonte de apoio social informal, composta por pessoas próximas ao ente adoecido, torna-se nesse momento um meio de enfrentamento e compartilhamento, seja ele de afeto ou de descanso para o cuidador principal.

"[...] em casa todo mundo vai estar perto, cuidando, dando amor e carinho, então essa é uma facilidade [...]." (A1)

Nota-se que, em alguns momentos, a fonte de apoio informal é ausente, o que pode gerar desconforto e desgaste ao cuidador principal. 
“[...] não é fácil a gente ficar no hospital querendo uma troca e, às vezes, a gente não consegue, às vezes a gente tem que ficar direto [...]" (A2)

Portanto alguns cuidadores entrevistados também manifestaram sentimentos de desconforto e solidão pela falta de apoio de outros familiares, gerando crises no seu desempenho, em que a habitual relação de afeto e de reciprocidade foi adicionada a uma relação de imperiosa necessidade de fazer pelo outro, sendo este fazer muitas vezes retraído pela evolução da doença, que acaba os levando a vivenciar sentimentos de impotência e sofrimento.

O apoio social formal, oferecido pelos trabalhadores do hospital, gerou aproximação e amizades, conquistadas pelo tempo de hospitalização do seu familiar, que proporcionou ao cuidador suporte assistencial e formação de vínculos afetivos, sentimentos de acolhimento assistencial e sensações de alegria.

"Não tive dificuldade nenhuma com ninguém, nem com médico, enfermeiro, técnico, faxineiro, porteiro [...] eu fiz uma amizade com todo mundo aqui no hospital [...] é como se fosse uma família para mim." (A5)

"[...] quando eu chamo sou muito bem atendida, então estou muito feliz com o atendimento daqui." (A6)

O aspecto religioso é quase sempre exaltado quando o ser humano se encontra em situações de fragilidade biopsicossocial, dessa forma a crença em forças sobrenaturais, ou resoluções de seus problemas pelo desenvolver do próprio destino, acaba por serem presentes na vivência dos adoecidos e refletem nos significados das vivências dos cuidadores desse indivíduo, sendo estes aspectos religiosos presente nas seguintes falas.

“[...] sou uma pessoa evangélica, tenho muita fé em Deus[...] Que seja feita a vontade de Deus, se ele estiver de tirar ela, que ele tire, mas sem dor $[\ldots]^{\prime \prime}(\mathrm{A} 5)$

“[...] tem que está buscando força em Deus, a fé em Deus que nos sustenta se não a gente desiste." (A7)

Portanto, enfrentar esse momento de doença com fé, crença em Deus, permite a sensação de amparo, força, perseverança e sustendo do cuidador para enfrentar as dificuldades advindas de seu papel.

\section{5) Vivências relacionadas ao ambiente hospitalar e domiciliar}

Por meio dos relatos dos cuidadores, tornou-se possível verificar que as vivências relacionadas ao ambiente hospitalar foram variadas, caracterizando o atendimento dos profissionais de saúde como bom e seguro.
“[...] a gente sabe que ela está em um lugar bom, que ela está sendo bem cuidada [...]" (A3)

"Aqui eu não estou tendo nenhuma dificuldade, eu tive em casa por não saber como locomover, estar mexendo muito com ela, mas aqui eu estou tendo todos os cuidados, toda ajuda." (A8)

Observamos que o ambiente hospitalar e o atendimento da equipe de saúde para o cuidador são vistos com a finalidade de controlar sintomas e como forma de ajuda nos cuidados diários, possuem acesso a informações do tratamento e auxilio a realizar cuidados mais complexos. Apesar de o ambiente hospitalar geralmente despertar sentimentos desconfortantes tanto para o cuidador quando para o enfermo, eles entendem que o hospital é o local mais adequado para os cuidados na situação que o paciente se encontra e alguns cuidadores sentiram-se acolhidos e bem assistidos no auxilio dos cuidados prestados ao seu ente querido.

Outro relato descreve a dificuldade de vivenciar diariamente o ambiente hospitalar, permeado pelo sofrimento, rotinas e em lidar com a morte, esse fato que é intensificado devido ao ambiente ser compartilhado por outros enfermos que evoluíram a óbito, gerando sensações emocionais negativas e medo, relacionado à iminente morte do seu ente querido.

“[...] muito difícil a gente ver alguém morrer do lado e ultimamente tem acontecido muito. [...] aqui já morreu dois, isso é mais difícil para gente, eu acredito que até para o paciente [...]" (A7)

Portanto, os cuidadores relataram as situações marcantes que tiveram destaque no cotidiano do cuidado ao seu ente querido. As situações mais marcantes tiveram relação com as complicações do câncer, medo da morte de seu ente querido e foram permeadas de sentimentos de dor e sofrimento. Assim, é necessária a ajuda profissional para a abertura de espaço para verbalização de fontes de problemas vividas pelo cuidador, fornecimento de informações e esclarecimentos de percepções e dentre outros. Logo, a enfermagem, neste contexto, pode também se inserir como uma provedora de apoio, facilitadora de relacionamentos, sendo de fundamental importância que o profissional conheça as complexidades e diferentes necessidades de apoio a este grupo, para que possa fornecer assistência de forma sensível e satisfatória.

Os cuidadores também relataram a expectativa de seu ente querido ser cuidado no domicílio com apoio da equipe de saúde do hospital em cuidados paliativos domiciliares.

“[...] eu espero agora que falaram que vai ter um acompanhamento paliativo domiciliar [...]. E eu estou na esperança disso hoje, que como minha mãe não vai poder vir mais no ambulatório nas consultas, pelo menos eles vão em casa. Isso aí eu acho que vai facilitar, melhorar para gente como 
familiares [...]" (A1)

Apesar de o ambiente hospitalar ter assistência vinte quatro horas e representar para o cuidador um suporte ao seu ente querido, é gerador de desconfortos, ansiedades, medos e angústias, disseram que, se tivessem a assistência domiciliar e suporte necessário, preferiam o conforto do lar para seu ente querido doente:

"[...] a gente quer pegar o paciente e levar para casa para gente cuidar porque aqui a gente vê muita coisa, muitas situações diferentes [...]" (A3)

"[...] gostaria de poder que ele estivesse uma assistência para irmos para casa, só que em casa ele não vai ter a assistência que ele está tendo aqui [...] quando for possível me dar um suporte para que a gente pudesse ir para casa, isso aí a gente não sabe quando é que vai acontecer, o final, assim como pode ser rápido, pode demorar, então é muito desgastante para gente, para família ficar aqui no hospital [...]." (A7)

Constatamos que seus entes queridos passam por situações difíceis durante o processo terapêutico, por se separarem de seu meio social para se submeterem a procedimentos que, geralmente, consistem em tratamentos agressivos, dolorosos e invasivos, e ao vivenciar toda essa situação, apesar da vontade de levar seu ente querido e retornar para seu cotidiano domiciliar. Esse desejo é superado pelo medo de não ter continuidade da assistência hospitalar, porém destaca todo o desgaste que é ser cuidador no ambiente hospitalar.

\section{DISCUSSÃO}

A carga de sofrimento trazida pelo câncer não é individual como identificado neste estudo, entendeu-se que os infortúnios enfrentados pelo doente são também vivenciados pelos que o cercam. Os resultados permitiram conhecer algumas características sócio demográficas, ou seja, quem são esses sujeitos e compreender as suas percepções em cuidar de um familiar com câncer em cuidados paliativos.

O diagnóstico de câncer na família provoca um abalo emocional, uma vez que é uma doença temida e indesejada, e é um evento inesperado dentro do núcleo familiar ${ }^{21}$. E quando se trata de demandar cuidados a uma pessoa doente, é a mulher que assume esse papel naturalmente, permanecendo a visão de que ela é a principal fonte de cuidado da família ${ }^{12}$.

Tal como neste estudo, pode ser observado em outras pesquisas $^{11}$, que cuidadores com grau de instrução diferenciado são afetados pelos mesmos problemas, mostrando com isso, que o senso comum em associar o alto grau de instrução a facilidades no cuidado nem sempre se aplica a realidade.

O cuidador, em sua maioria, busca atender tanto às necessidades básicas do paciente, como atender as suas vontades e desejos, o que é dificultado tanto pela falta de tempo disponível, quanto por trabalharem fora e pela falta de condições financeiras ${ }^{23}$.

Percebeu-se que todos os cuidadores possuíam vínculo de parentesco com o paciente, porém há a necessidade de aumento na frequência de outros familiares no suporte, pois foi visualizada que durante o cuidado ocorre evidência de um cuidador em detrimento aos outros, tendo o cuidador principal de renunciar seus sonhos e desejos, por vezes, esquecendo-se de sua qualidade de vida e autocuidado ${ }^{13}$.

E conforme ocorre o avanço da doença, os cuidados ao paciente se intensificam, ao passo que o olhar em relação ao cuidador é diminuído, e suas necessidades são quase que desconsideradas, além do que o cuidado se torna árduo podendo gerar sobrecarga física, emocional, financeira e outras.

A percepção dos participantes sobre a assistência em cuidado paliativo se relaciona com o conceito de cuidados paliativos, que consiste em uma assistência, que objetiva a melhoria da qualidade de vida do paciente, diante de uma doença que ameace a vida, por meio da prevenção e alívio do sofrimento ${ }^{14}$. Porém, mesmo nos casos em que a morte se aproxima inevitavelmente, é fundamental que o cuidador familiar seja instruído nesse momento, tendo clareza do estado real da doença ${ }^{15}$.

Pode-se dizer que o papel do cuidador se modifica, aperfeiçoase, adapta-se, pois, o cuidador acompanha o paciente nas várias etapas da doença, atravessando-as, em geral, de modo árduo, contendo importante carga de trabalho dispensada ao paciente, vivências que tendem a se intensificar com a evolução da doença ${ }^{11}$. O cuidado direto ao paciente necessita de ações técnicas como, administração de medicamento, auxílio na nutrição e na higiene, como também ações para apoio emocional, como carinho, afeto e companhia em todos os momentos solicitados pelo paciente. O papel do cuidador em cuidar de um familiar é de fundamental importância na trajetória do tratamento para enfrentamento de todas as dificuldades que vierem acontecer ${ }^{21}$.

Surgem, durante o ato de cuidar, sentimentos contrastantes, pois, se por um lado, o cuidador tem afeto, carinho e sente prazer em atender as demandas de seu parente, por outro lado os sentimentos de cobrança, fuga e vigilância permanentes são reforçados constantemente ${ }^{11-16}$. O comportamento de fuga e esquiva está relacionado aos sentimentos negativos que a doença provoca na família, principalmente em relação à morte ${ }^{24}$

Depois da notícia do diagnóstico, dá-se início a uma crise familiar e a mesma busca por estratégias de enfrentamento para reagir ao problema ${ }^{10}$. Surgem variadas dificuldades, assim a conduta de cuidar de um paciente oncológico promove a vivência de medos, o que se torna constante para os cuidadores, medo de não prestar os cuidados adequados, do sofrimento físico e 
psicológico, da dor, e, acima de tudo, o medo da morte, o que traz o desespero e sentimento de impotência ${ }^{25}$.

Para o enfrentamento da doença são criados pelos cuidadores fontes de apoio. Sendo a religião uma das mais importantes fontes de apoio que a família costuma recorrer. Essa estratégia é descrita como suporte e conforto, por ter a capacidade de proporcionar a serenidade durante as adversidades da doença ${ }^{19}$.

Mediante todo contexto, as competências de enfermagem recebem destaque nos cuidados paliativos. Tanto para a equipe, quanto para o paciente, familiares e para a instituição, é necessário que esse profissional tenha habilidades de comunicação, pois estas asseguram o melhor desenvolvimento de suas práticas clínicas. Atuam em prol da comunicação eficaz, aberta e adaptada ao contexto terapêutico, visando à interação familiar, à negociação de metas assistenciais acordadas com o paciente e sua família de modo a coordenar e alcançar o cuidado planejado. Trata-se de cuidados sensíveis e de educação, que demandam ações de proximidade física e afetiva para que muitas das orientações se efetivem na prática ${ }^{3}$.

O ambiente em que o sujeito está inserido gera expectativas, ansiedades, temores, satisfação, sendo ele hospitalar ou domiciliar. O hospital é visto como um local que pode trazer alívio do sofrimento, maior conforto ao paciente, como também amenizar o próprio sofrimento do cuidador ${ }^{11}$. No entanto, há dificuldade em lidar com a morte, fato que é intensificado devido ao ambiente ser compartilhado por outros enfermos que evoluíram a óbito, aumentando o abalo emocional e o medo relacionados à iminente morte de seu ente querido. Para outros, o lar proporciona uma maior satisfação porque podem participar ativamente do processo de cuidado ${ }^{18}$, sem a necessidade de seguir a rigidez das regras e horários como em um hospital. Permite ainda sensação de aconchego, conforto, calor e proteção ${ }^{3}$.

A limitação maior do estudo relacionou-se à pouca literatura atualizada sobre o assunto. A temática do cuidado paliativo, ao incluir os cuidadores familiares, sugere espaço para muitas outras pesquisas acadêmicas voltadas ao cuidador, além de promover sensibilização em enfermeiros.

\section{CONCLUSÃO}

O estudo permitiu conhecer qual é a percepção do cuidador do paciente com câncer em cuidado paliativo. Durante a pesquisa, foi possível notar que a maioria dos participantes não tinham conhecimento algum e tão pouco arriscavam dizer do que se trata o cuidado paliativo, e a minoria demonstrou ter alguma consciência sobre o tema, o qual expressara por meio de associações como "alívio da dor", "quadro sem possibilidade de cura" e "minimizar o sofrimento".

As dificuldades dos cuidadores desveladas durante o estudo refletem o despreparo pessoal aliados à sobrecarga física, emocional e à precariedade nas fontes de apoio informal, evidenciado pelo baixo nível de ajuda que os cuidadores principais recebiam de familiares e pessoas próximas. Apesar de o estudo demonstrar que a fonte de apoio formal foi positiva, há necessidade de os profissionais de saúde intensificarem as orientações quanto aos sintomas, aos cuidados diretos ao paciente e ao auxílio psicológico e ao apoio emocional ao cuidador, mesmo por que os cuidadores, em sua maioria, ficam em segundo plano em virtude dos problemas do paciente enfermo, o que não deveria acontecer, pois é notório o desgaste deles diante de todas essas circunstâncias. A equipe de enfermagem pode contribuir identificando e treinando as famílias e os cuidadores dos usuários, envolvendoos na realização de cuidados respeitando seus limites e potencialidades, abordando o cuidador como sujeito do processo e executor das ações, elaboração de reuniões para cuidadores e familiares, para esboçar suas dificuldades em busca de sua melhoria e da própria assistência de enfermagem.

Possibilidades futuras envolvem a investigação sobre o cuidador e suas necessidades, diante da equipe multiprofissional, e do apoio hospitalar para identificar possíveis problemas e proporcionar suporte para que esses sejam resolvidos, e, por sua vez, melhorar também a qualidade de vida do cuidador principal.

\section{REFERÊNCIAS}

1. Pessini L, Bertachini L. Humanização e Cuidados Paliativos. 6 ed. São Paulo: Loyola; 2014.

2. Figueiredo NMA, Leite JL, Machado WCA, Moreira MC, Tonini T. Enfermagem Oncológica: conceitos e práticas. São Caetano do Sul: Yendis Editora; 2009.

3. Carvalho RT, Parsons HA, organizadores. Manual de cuidado paliativo ANCP. São Paulo: Academia Nacional de Cuidados Paliativos. 2. ed.; 2012.

4. Kovács MJ. A caminho da morte com dignidade no século XXI. Rev. Bioét. 2014; 22(1): 94-104.

5. Cruzeiro NF, Pinto MH, Cesarino CB, Pereira APS. Compreendendo a experiência do cuidador familiar com câncer fora de possibilidade de cura. Rev.
Eletr. Enf. 2012 Out-Dez [acesso 2016 Nov 12]; 14(4): 913-21. Disponível em: <https://www.fen.ufg.br/fen_revista/v14/n4/pdf/v14n4a20.pdf>.

6. Streid J, Harding R, Agupio G, Dinat N, Downing J, Gwyther L, et al. Stressors and resources of caregivers of patients with incurable progressive illness in sub - Saharan Africa. Qual Health Res. 2014 Mar; 24(3): 317-28. doi: 10.1177/1049732314523682.

7. Pereira SM, Fonseca AM, Carvalho AS. Burnout in palliative care: a systematic review. NursEthics. 2011 May; 18(3): 317-26. doi: 10.1177/0969733011398092.

8. Teixeira E. As Três Metodologias: acadêmica, da ciência e da pesquisa. 10. ed. Petrópolis: Vozes; 2013 
9. Bardin L. Análise de conteúdo. Lisboa: Edições 70; 2011.

10. Farinhas GV, Wendling MI, Dellazzana-Zanon LL. Impacto Psicológico do Diagnóstico de Câncer na Família. Pensando fam. 2013 Dez [acesso 2017 Nov 16]; 17(2):111-129. Disponível em: < http://pepsic.bvsalud.org/pdf/penf/ v17n2/v17n2a09.pdf >

11. Vasconcelos EV. Representações sociais do câncer para cuidadores familiares de pacientes fora de possibilidades de cura: Implicações para o cuidado [dissertação]. Belém (PA): UEPA; 2012 [acesso 2016 Dez 09].Disponível em: <http://paginas.uepa.br/ppgenf/files/pdfs/DISSERTAO_ESLEANE.pdf >.

12. Wegner W, Pedro ENR. Os múltiplos papéis sociais de mulheres cuidadorasleigas de crianças hospitalizadas. Rev. Gaúcha Enferm. 2010 Jun [acesso 2017 Nov 05]; 31(2): p. 335-342. Disponível em: < http://www.scielo.br/pdf/rgenf/ v31n2/19.pdf >

13. Almeida SSL, Martins AM, Rezende AM, Schall VT, Modena CM. Sentidos do cuidado: a perspectiva de cuidadores de homens com câncer. Psico-USF. 2013 Dez [acesso 2017 Out 24]; 18(3): 469-478. Disponível em: <http://www.scielo. br/pdf/pusf/v18n3/a13v18n3.pdf >.

14. Ministério da Saúde [BR], Secretaria de Atenção à Saúde, Departamento de Regulação, Avaliação e Controle,Coordenação Geral de Sistemas de Informação. Manual de Bases Técnicas da Oncologia - Sia/Sus - Sistema de Informações Ambulatoriais. 13. ed. Brasília: Ministério da Saúde; 2011.

15. Neme CMB. Psico-oncologia: caminhos, resultados e desafios da prática In: Ne-NEME, CMB, organizador. Psico-oncologia: caminhos e perspectivas. São Paulo: Summus; 2010.

16. Amador DD, Reichert APS, Lima RAG, Collet N. Concepções de cuidado e sentimentos do cuidador de crianças com câncer. Acta Paul Enferm. 2013 NovDez [acesso 2017 Nov 10]; 26(6): 542-546. Disponível em: < http://www.scielo.
br/scielo.php?pid=S0103-21002013000600006\&script=sci_arttext >.

17. Inocenti A, Rodrigues IG, Miasso Al. Vivências e sentimentos do cuidador familiar do paciente oncológico em cuidados paliativos. Rev Eletr Enf. 2009; 11(4): 858-65.

18. Ministério da Saúde[BR]. Caderno de atenção domiciliar. Brasília: Ministério da Saúde; 2013

19. Oliveira MS, Fernandes AFC, Galvão MTG. Mulheres vivenciando o adoecer em face do câncer cérvico-uterino. Acta Paul Enferm. 2005; 18(2): 150-5.

20. Instituto Nacional de Câncer José Alencar Gomes da Silva. Estimativa 2018 incidência de câncer no Brasil. Rio de Janeiro: INCA; 2017. 128 p.

21. Mutro MEG. Vivência do cuidador familiar de paciente com câncer [dissertação]. Botucatu (SP): UNESP; 2012 [acesso 2017 Nov 10]. Disponível em: <https://repositorio.unesp.br/handle/11449/96461>.

22. Vasconcelos EV. Representações sociais do câncer para cuidadores familiares de pacientes fora de possibilidades de cura: Implicações para o cuidado [dissertação]. Belém (PA): UEPA; 2012 [acesso 2016 Dez 09]. Disponível em: <http://paginas.uepa.br/ppgenf/files/pdfs/DISSERTAO_ESLEANE.pdf >.

23. Guimarães CA, Lipp MEN. Um olhar sobre o cuidador de pacientes oncológicos recebendo cuidados paliativos. Psicol. teor. prat. 2011 Ago; 13(2):50-62

24 Martins, CBS, Silva N Filho, Pires MLN. Estratégias de coping e o impacto sofrido pela família quando um dos seus está em tratamento contra o câncer. Psico Saúde. 2011 Jan-Jun; 19 (1-2): 11-18.

25 Santos EM, Sales CA. Familiares enlutados: compreensão fenomenológica existencial de suas vivências. Texto contexto - enferm. 2011; 20(spe): 214-22.

\section{Como citar este artigo/How to cite this article:}

Cunha AS, Pitombeira JS, Panzetti TNP. Cuidado paliativo oncológico: percepção dos cuidadores. J Health Biol Sci. 2018 Out-Dez; 6(4):383-390. 